\title{
CONCEPCIONES DE TRABAJO Y RELACIONES SOCIALES EN EL USO DE LA TIERRA ENTRE LOS MACHIGUENGA DEL ALTO URUBAMBA
}

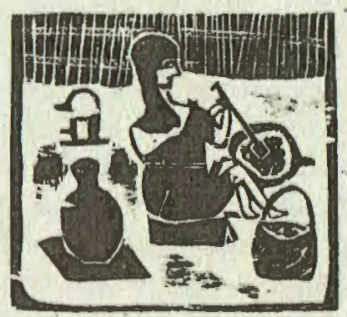

por: Dan Rosengren*

In this article the autbor discusses the use of land as a resource or as merchandise. It points out two concepts current in the Amazon: that of the Amazonian Indian -in this case the Machiguenga- and that of the western world, this is, that of the migrants. He analyzes the use, by the Indians, of a wide variety of resources through settlement patterns and subsistence practices that permit them to cover their social needs, something that does not bappen among the migrants. He also examines the different concepts of the work process related to property and production among Indians and migrants and the problems that result from contradictions within and outside of Indian society.
Dans le présent article, l'auteur traite comme point essentiel, l'usage de la terre soit comme ressource, soit comme marchandise. Il montre les deux conceptions en vigura en Amazonie: celle de l'bomme amaxonien dans ce cas les Machiguengas et celle de l'homme occidental á savoir les immigranis.

Il analyse l'usage, quant aux indigénes, de la grande variété des resssources á travers le modéles d'emplacement et les pratiques de subsistance qui leur permettent de satisfaire les besoins sociaux, yce qui n'existe pas chex les inmigrants.

De même l'auter examine les différentes conceptions du processus du travail dans le systéme de la production el de la propriété chez les indigénes et les immigrants mais aussi les problémes qui proviennel des ces divergences á l'intérieur et á l'extérieur de la société indigéne.

\footnotetext{
* Antropólogo. Universidad de Göteborgs. Gothenburg, Suecia.
} 
Considerando los derechos a la tierra y otros recursos naturales en general, los grupos nativos de la selva y montaña peruanas están experimentando una situación de dificultad creciente en relación a los proyectos de colonización y las demandas de la sociedad nacional. El impulso que el gobierno de Belaúnde dio a la formación de los llamados "neolatifundios de la selva" (grandes empresas de capital intensivo y propiedad privada), y a utilizar la tierra y el trabajo para una rápida integración del área en la economía de mercado, es algo para lo que muy pocos o ninguno de los grupos nativos están preparados en el presente.

Vistas a la luz de las experiencias de otros países de sudamérica y el mundo, las perspectivas futuras de los grupos nativos en el Perú son realmente deprimentes, si es que no se hace algo pronto. $\mathrm{La}$ introducción a las Comunidades nativas era una medida necesaria para adquirir un mínimo grado de seguridad para los grupos nativos, pero está lejos de ser suficiente el solo reservar tierras para estos grupos y por otro lado dejar las fuerzas de la economía de mercado libres en el área. Uno debe darse cuenta que las Comunidades nativas no son ninguna isla, sino que más bien están comprendidas en el sistema sociocultural más grande del estado peruano y, por lo tanto, son altamente susceptibles a los cambios incontrolables inducidos por fuerzas externas. Por ende, solo diez años después de su introducción, podemos observar en las Comunidades nativas un conflicto entre los diferentes y en muchos aspectos contradictorios sistemas que, a la larga, no podrán coexistir. El presente trabajo estará dirigido a uno de los aspectos centrales de este conflicto: las relaciones sociales en el uso de la tierra entre los Machiguenga del área del Alto Urubamba en el Departamento del Cuzco; área que ha sido sometida a la colonización espontánea de los campesinos llamados colonos, principalmente de las tierras altas de los alrededores durante los últimos 20-25 años.

Como consecuencia, los Machiguenga han sido crecientemente comprometidos en la economía de mercado, generalmente para su propia desventaja. Este proceso los ha llevado a las siguientes condiciones: a) han sido forzados a permitir la sobreexplotación de importantes recursos naturales como la caza salvaje, la pesca y ciertas plantas dentro de sus territorios; b) son engañados o forzados a vender sus productos muy baratos y a comprar otros artículos a precios más altos; y c) cuando trabajan para los migrantes, con frecuencia se les paga salarios sustancialmente menores que los pagados a los no-machiguéngas. A veces se han reportado casos en que los salarios se pagan en especies en vez de efectivo, y el pago de deudas se hace con trabajo, casos en que los Machiguenga viven más o menos como esclavos.

Sin embargo, para entender el fondo de esta confrontación, es necesario reparar en cómo los dos grupos - Machiguengas y colonos- conciben la tierra; siendo ésta el más importante de los medios de producción de los dos grupos. Para hacer esto, consideraremos la reciente discusión sobre tenencia de la tierra dentro de la Antropología social; más específicamente, el tema de la tierra como recurso o como mercancía y las relaciones de propiedad resultantes.

Roy Ellen, al discutir las inadecuaciones y tergiversaciones recurrentes en el enfoque jurídico relativista en Antropología, sostiene que los "errores". de los legalistas, 
we lusun principalmente en la ausencia de una distinción clara entre bienes muebles e Inmusebles. Esta distinción es importante porque, simultáneamente, es una distinción entre recurso y mercancía. La tierra, por ejemplo, siendo un bien inmueble, no puede ser apropiada para el consumo como las plantas que son bienes muebles que crecen sobre ella. Así, explica Ellen (1977: 69), la tierra "no es una mercancía verdadeti, sino un recurso sin un valor general de cambio".

En la distinción entre recurso y mercancía, es crucial la clase de valor (es) inherente a un objeto. De acuerdo con la teoría del valor del trabajo (cf 1954: 43-87) de Karl Marx, se distinguen dos clases: valor de uso y valor de cambio. El valor de uso de un objeto, consiste en el grado hasta el cual el objeto cumple las funciones técnicins para las que fue producido. El valor de cambio, es el mismo que el precio de ditho objeto; y aunque el dinero es usado para medir el precio, lo que se intercambia es el tiempo de trabajo socialmente necesario, invertido en la producción de los objetos intercambiados. El dinero es sólo el equivalente para todo uso. Representa el tlempo de trabajo invertido anteriormente, y es necesario en una economía con una circulación de mercancías compleja; esto es, en los sistemas económicos donde un producto debe ser vendido por dinero con el que se pueden comprar otros productos $(P-M-P 1)$.

Entonces, se podría decir que el precio de mercado de las mercancías cambiadas, es equivalente con el tiempo de trabajo socialmente necesario, requerido para producir los objetos medidos en el cambio. Ya que no se ha invertido ningún trabajo en la tierra, ésta no tiene ningún valor de cambio, como demuestra Ellen. Aunque la tierra puede tener un valor de uso, no puede ser consecuentemente definida como una verdadera mercancía, sino como un recurso. Sin embargo, Marx estaba bien advertido del hecho de que los objetos que no eran verdaderas mercancías, con frecuencia entraban al mercado y eran comprados y vendidos. Dice al respecto (1954: 105):

"Los objetos que por sí mismos no son mercancías, tales como la conciencia, el honor, etc.; son capaces de ser ofrecidos en venta por sus poseedores y por esto adquirir, a través del precio, la forma de mercancías. Por consiguiente un objeto puede tener un precio sin tener valor. En este caso el precio es imaginario...

Por otro lado, la forma precio imaginario a veces puede encubrir, directa o indirectamente, un valor-relación real; por ejemplo, el precio de la tierra no cultiva$\mathrm{da}$, sin valor porque ningún trabajo humano ha sido incorporado a ella".

Siguiendo a Marx, la teoría del valor del trabajo era aplicable sólo en el análisis de economías con una compleja circulación de mercancías (ver más arriba). Sin embargo, una apreciación crítica de Raymond Firth (1979), argumenta que la teoría también es válida en economías de circulación simple de mercancías, esto es, donde los productos son inmediatamente cambiados por otros productos sin intervención de dinero (P - P1). La razón por la que Marx creía que su teoría del valor del trabajo sólo se aplicaba a economías de mercado, era la creencia de que sólo en estas economías tal trabajo era una mercancía que podía ser comprada y vendida. A fin de demostrar la amplia aplicabilidad de la teoría de Marx, Firth (1979: 192), discute la 
economía consuetudinaria Tikopian y concluye que "hay una visible consideración del trabajo en términos de escasez, de Fekau (concepto tikopian del trabajo que significa sacrificio de la comodidad y el ocio, D.R.) en términos de uso competente de los recursos de energía del hombre (y la mujer)".

No es necesario inquirir en si la afirmación de Firth es válida o no (pero para un debate interesante ver M. Godelier 1969 y la réplica de B. Bradby 1977). Que sea suficiente cerciorarse que la distinción entre "mercancía" y "recurso" es importante aún en economías de circulación simple de mercancías, y que el factor distintivo es si el trabajo -o la energía humana- está incorporado o no en el objeto. Esta distinción no es sólo académica, sino que también afecta las concepciones y las relaciones de propiedad. Un recurso, no teniendo valor de cambio, no puede ser vendido y comprado como una mercancía y, como consecuencia, no puede ser poseído en el mismo sentido en que una mercancía es siempre poseída.

En lo concerniente a las relaciones de propiedad en general, debe tenerse en mente que éstas son relaciones sociales entre los hombres y no relaciones entre hombres y objetos. Una relación de propiedad, entonces, regula una serie de derechos y deberes que el poseedor tiene en relación al objeto y a otras personas. El poseedor puede tomar decisiones concernientes al objeto, decisiones que a pesar de afectar a otras personas, no pueden ser previstas (amenos que otras leyes sean quebrantadas por la decisión). Sin embargo, poseer un objeto no está necesariamente limitado a una persona; frecuentemente, especialmente en sociedades igualitarias, los derechos conectados con un objeto están vertidos en un grupo de personas que pueden ejercer estos derechos comunalmente. En las sociedades no-igualitarias, con frecuencia los derechos están vertidos en grupos de orden jerárquico, a diferentes niveles de las jerarquías, donde los de abajo están subordinados a los de arriba. Generalmente tales jerarquías terminan, por lo menos teóricamente, con un rey, un parlamento o aún un dios supremo como último poseedor de todo. Sin embargo, en la práctica hay una tendencia general a que el más alto en las jerarquías, tenga el menor control sobre los objetos individuales y también la posesión simbólica.

Los derechos individuales al uso de la tierra y otros recursos naturales, a menudo han estado caracterizados por el término "usufructo"; pero el significado de este término es vago y, consecuentemente, ha estado siendo usado para cubrir y describir una amplia variedad de condiciones en el uso del recurso. Mientras que los más altos niveles de derechos generalmente están basados ideológicamente (por ejemplo, que el rey sea instalado para regir por la voluntad de Dios en un país específico y que, por tanto, tenga allí derechos sobre la tierra y sus pobladores), en las sociedades nocapitalistas la inversión de trabajo en el objeto, es hecha en relación a aquellos que tienen derechos individuales (cf Bohannan 1963, Gluckman 1965).

Maurice Godelier (1978), en cierto sentido ha entendido este argumento cuando acentúa que es crucial que distingamos entre "propiedad abstracta", por un lado, y "propiedad tal como existe en un proceso concreto de apropiación", por otro. 
Según Godelier (1978: 400) la "propiedad toma la forma de una serie de reglas abstractas que determinan el acceso, control, utilización, transferencia y transmisión de cualquier forma de realidad social susceptible de discusión". Sin embargo, y encuentro esto importante, la propiedad en sus formas concretas "sólo existe cuando está vigente en un proceso apropiativo" (1978: 404), esto es, en el proceso de trabajo (1978: 406).

Considerando la presente discusión, se concluiría que las relaciones de propiedad primariamente son un proceso de apropiación, y sólo secundariamente un sistema de reglas establecidas. Parece que - aunque con frecuencia ésto ha sido entendido vagamente, especialmente en lo que respecta a las sociedades igualitarias, no jerarquizadas - el velo puesto por nuestra propia herencia cultural, ha impedido un entendimiento adecuado de las condiciones. Del mismo modo, nuestra necesidad de científicos de describir las diferentes situaciones sociales y hacerlas inteligibles para nosotros mismos y para una audiencia más amplia, puede habernos forzado a dar indebida importancia (y quizás a inventarlas) a reglas que pueden funcionar como un mapa cognoscitivo cuando tratamos de orientarnos en un paisaje social desconocido.

De acuerdo a lo dicho arriba, vemos que hay una diferencia importante entre tierras cultivadas y tierras sin cultivar. La primera es una mercancía, mientras que la última es "solamente" un recurso. También hemos visto que lo que distingue a una de otra, es si se ha invertido o no trabajo en ella. Podemos concluir en que, lo que los derechos de una parcela de tierra en particular realmente confieren, desde esta perspectiva teórica, no tienen nada que hacer con la tierra en sí misma, sino con el control del trabajo allí realizado y con el producto de ese trabajo. La tierra es un objeto inmóvil y no puede conferir derechos y obligaciones por sí misma (aunque ideológicamente puede ser representada de esa manera); mientras que la fuerza de trabajo y los productos agrícolas son objetos móviles que pueden ser cambiados por otros objetos y, por tanto, ser apropiados individualmente.

Las mismas distinciones hechas aquí, fueron realizadas también, por ejemplo, en el derecho romano (cf. Gluckman 1965; 134), y eran válidas en Europa aún en la época medieval (cf. Marc Bloch 1965: 113-120). Sin embargo, en ese tiempo la tierra comenzaba a ser vista como una mercancía, a fin de hacer posible la acumulación de la propiedad (Marc Bloch 1965: 132 f). En la época de la conquista española de Sudamérica, estos cambios fueron rápidamente introducidos y también aplicados por los conquistadores en el Nuevo Mundo ( $c f$. Ford 1955: 33ff). Desde aquellas épocas ha habido una tendencia a considerar las tierras poseídas comunalmente como "primitivas" y "atrasadas", mientras que las tierras privadas han sido vistas como "civilizadas" y como signo de "desarrollo". Estas ideas han impregnado toda la cultura occidental, y es con estas nociones de propiedad que los campesinos migrantes llegan al área del Alto Urubamba. 


\section{LOS MACHIGUENGA Y EL USO DE LOS RECURSOS}

\section{Patrones de Asentamiento}

Los Machiguenga que habitan la selva del Alto Urubamba, constituyen un grupo de 2,500 a 3,000 individuos. Antiguamente vivían dispersos en pequeños grupos a lo largo de los tributarios del río Urubamba. Con el boom de la zarzaparrilla y el caucho, durante la segunda mitad del siglo XIX, fueron trasladados y concentrados por la fuerza alrededor de algunos campamentos de recolección de zarzaparrilla y caucho, para tenerlos disponibles como fuerza de trabajo para las compañías explotadoras.

Aún hoy podemos encontrar las más grandes concentraciones de Machiguengas alrededor de estos antiguos campamentos, y también aquí encontramos a las actuales comunidades nativas. En el área del Alto Urubamba existen siete Comunidades Nativas (Chirumbia, Koribeni, Sangobatea, Shimaa/Shimendato, Malanquiato, Matoriato y Pogentimari), pero solo una de ellas - Koribeni- está legalmente reconocida.

Los grupos de asentamiento Machiguenga no son grupos corporados locales y no tienen noción de territorialidad, esto es, ideas de un grupo particular que tienen "derechos" exclusivos de acceso y control sobre cierta área. Antes de la imposición de las Comunidades nativas, estos grupos no gozaban de ningún privilegio a la tierra en la cual estaban establecidos, y no se podía negar a nadie el derecho a trasladarse a cualquier área. Aunque los grupos están establecidos a lo largo del curso de agua, ésto no significa que controlan o "poseen" esa tierra. Siendo una característica geogrâfica prominente, el río es meramente un punto de referencia que indica a los otros dónde puede encontrarse un grupo en particular.

Aunque la introducción de las comunidades nativas comienza en 1974, ésto necesariamente ha significado que el territorio disponible para los Machiguenga ha devenido más restringido que los antiguos patrones de asentamiento, que en gran parte habían sido mantenidos sin modificación (Rosengren 1983).

Aún las viviendas Machiguenga están dispersas en grandes áreas y no existe una real estructura de nucleo poblado. Por el contrario, las viviendas se encuentran ampliamente dispersas en o en la vecindad inmediata de las chacras familiares.

Ocasionalmente pueden encontrarse pequeños grupos de dos o tres casas, pero generalmente los vecinos más cercanos viven de 10 a 20 minutos de distancia a pie.

Sin embargo, en las comunidades nativas más densamente pobladas, uno puede notar que los asentamientos han devenido más permanentes que antes. Antiguamente las casas eran abandonadas después de tres o cinco años, y los nuevos asentamientos generalmente eran levantados en otra parte. Actualmente, las casas son habitadas por largo tiempo y cuando se construye una nueva se hace en el miso sitio que la anti- 
gun. Hasta cierto punto se puede decir que el antiguo cambio de asentamientos estuvo relacionado a la decreciente productividad de las chacras, pero también a otros lictores; la muerte de un adulto miembro de la comunidad doméstica o los conflictor personales, han jugado un rol. Pero hoy en día, tales factores se tienen menos en cuenta, pues surgen otros como la reducida cantidad de tierra disponible para los wentamientos, como consecuencia de la relativa concentración de la población en las comunidades Nativas; además de la introducción permanente de la producción vendida al contado.

\section{Prácticas de Subsistencia}

La economía de subsistencia de los Machiguenga principalmente está basada en In agricultura de la chacra, pero la importancia de la caza, la pesca y probablemente lumbién la recolección, es considerable.

\section{Horticultura}

Durante sus andanzas en los bosques, los hombres Machiguenga están atentos a Iu aparición, entre otras cosas, de sitios apropiados para el establecimiento de nuevas chacras. Antes de decidir la ubicación de una nueva, se deben tener en cuenta varias consideraciones. Preferiblemente la parcela debe estar cubierta por árboles altos; debe tener la debida clase de suelo; la pendiente no debe ser ni muy empinada ni muy pequeña y el sitio no debe estar muy lejos de la casa.

Tomando en consideración todos estos factores, deciden dónde establecer una nucva chacra; como afirma Allen Johnson (1982: 415): localmente los Machiguenga pueden "encontrar la escasez en el medio de la abundancia".

Cada año se desmonta aproximadamente media hectárea de bosque, ya sea para LA extensión de una chacra en producción o como el inicio de una enteramente nueva. Cada parcela es trabajada, entonces, de tres a cinco años, dependiendo de su productividad, después de lo cual es dejada en barbeche. Esto significa que la extensión total de las chacras individuales Machiguenga, en promedio solo alcanza de 2.5 II 3 hectáreas.

La parcela escogida es desmontada al inicio de la estación seca (esto es, de Mayo a Junio), y es ulteriormente quemada al final de la estación seca o al comienzo de la estación lluviosa (esto es, entre setiembre y noviembre). Se hace la primera aiembra tan pronto como es posible, después de la quema. El deshierbe comienza caal inmediatamente y continúa por todo el tiempo que la chacra es cuidada y replanta- 
da. Hasta este momento el trabajo masculino ha predominado, pero con el comienzo de la cosecha la situación cambia, y de aquí en adelante la mayor parte del trabajo es realizada por mujeres.

Los cultivos comerciales son yuca, maíz y plátanos. Muchas variedades de estos productos son característicos y más o menos comunes en el área. Los derivados de determinadas especies particularmente la yuca, son distinguidas por los agricultores individuales y construyen subvariedades reconocidas solo individualmente. Una amplia variedad de plantas son cultivadas en las chacras al lado de los cultivos comerciales y se puede encontrar algunas sembradas con más de treinta plantas diferentes, sin incluir las diversas variedades y subvariedades. Sin embargo, la mayoría de las especies en estos multicultivos son plantadas en reducido número, mientras que hay una especie dominante. La yuca, generalmente, es el componente principal de todas las comidas, se le consume hervida, asada o es usada para hacer masato, shtea. La posición central de la yuca puede ser ilustrada por el hecho que las palabras para "comer", notsekatanaka (1), y "tener hambre", notsegakye, ambas están relacionadas a la palabra usada para yuca, tsekatsi.

Los tubérculos de yuca pueden conservarse por largo tiempo bajo tierra, pero después de haber sido extraídos deben ser consumidos prontamente o comenzarán a pudrirse; por ésto es cosechada contínuamente, cada uno o dos días, y con frecuencia se siembra una nueva planta inmediatamente después de que otra ha sido extraída. Esto significa que siempre habrá una abundante provisión de yuca a disposición de la familia y mucha de ella nunca será consumida. Dice A. Johnson (1983: 63): “... en sentido restringido (yo diría que engañoso), es un desperdicio que una gran cantidad de energía alimenticia no sea consumida nunca... los Machiguenga maximizan su autonomía a través de la sobreproducción".

Por el contacto creciente con representantes de la sociedad nacional, ha comenzado un proceso que está transformando el sistema económico que afecta directamente las prácticas agrícolas. Aunque los cultivos de subsistencia aún predominan, se está produciendo un aumento de la extensión para los cultivos comerciales de café, cacao, coca y achiote. De estos cuatro productos, sólo el primero está siendo recientemente introducido, mientras que los otros tres han sido cultivados por largo tiempo sólo para las necesidades de subsistencia. Sin embargo, hoy en día estos cultivos son producidos en mayor escala que antes y principalmente para el mercado. Es grande la importancia de estos cambios, aunque quizás ésta no sea evidente de inmediato en las condiciones presentes. Sin embargo, las consecuencias de este nuevo régimen agrícola serán sentidas en un futuro cercano.

\section{La Caza}

Aunque la importancia económica de la caza puede haber decrecido, ésta aún juega un rol ideológico muy importante ya que, en gran medida, esta actividad es la 
que hace que un hombre sea un Hombre. Así, por ejemplo, cuando un hombre sale de su casa para la chacra, siempre lleva un arma. En las comunidades nativas más aisladas el arma será el arco y las flechas, u ocasionalmente una escopeta; mientras que en las comunidades nativas más cercanas a los asentamientos de migrantes, generalmente sólo se lleva una honda y una bolsa de guijarros para cazar pájaros. Los Machiguenga no tienen tabúes para la caza de ciertos animales. Los tabúes contra el consumo de: jaguar (matsontsori, Pantera onca), venado (maniro, Mazama americana) y la concepción de que todas las serpientes (categoría que también incluye a las tortugas) y comedores de carroña son impropios para la comida; todo lo anterior no impide que los Machiguenga maten a esos animales. Especialmente las serpientes son muertas cada vez que es posible, pues son muy temidas.

La caza más común son diferentes clases de pájaros y monos. Entre los primeros tenemos la oropéndola, el guaco y varias especies de patos y gallinas. El mono más característico es el capuchino negro (Cabus apella), el que en Machiguenga es llamado Komangyinaro, término que también significa "mono". Los roedores como el armadillo son muy comunes, junto a estos son cazados una gran variedad de pájaros muy pequeños. Hoy en día animales como el tapir, la capybara, caimanes y osos son muy buscados pero muy raramente encontrados.

Generalmente la caza es una actividad muy solitaria, aunque ocasionalmente dos o tres hombres salen juntos si la caza se ha planeado para varios días. Estos equipos consisten de hermanos o cuñados. Antiguamente no había limitaciones territoriales y la única imposición que tenía un hombre que quería cazar era cuán lejos él deseaba caminar. Sin embargo, el área de caza estaba limitada a la distancia que un hombre podía cubrir desde muy temprano en la mañana hasta mediatarde. Además, parece que cuando la caza deviene escasa en determinada área, la familia se traslada a mejores territorios de caza. Actualmente, las Comunidades nativas y los campesinos migrantes, que se han instalado alrededor de los asentamientos Machiguengas, han detenido esta movilidad.

De la anterior resultan dos consecuencias: 1) se ha cazado tan intensamente en el territorio de las comunidades nativas, que ésto ha llevado al decaimiento de la reserva de caza y 2) cuando el retorno de la caza decrece, se caza menos. Uno se da cuenta de estas consecuencias en Matoriato, donde una extensa y aislada parte del territorio de la comunidad nativa ha sido reservado para la época de caza. Hasta 1981 la asamblea comunal de Matoriato no había permitido a nadie instalarse en esa área. Orna Johnson (1978: 56f) informa que en el área de Shimaa la caza es tan escasa que hoy en día prácticamente no tiene ninguna importancia económica.

\section{La Pesca}

La pesca es la más importante fuente de proteína animal para los Machiguenga. Es una actividad de todo el año, aunque durante la estación seca, en la cual es posi- 
ble pescar con veneno, es cuando más peces se obtienen. Sin embargo, como en el caso de la caza, se dice que la pesca era mucho mejor en los tiempos antiguos; aunque en lo más profundo del monte ("adentro") el resultado aún es muy bueno. La productividad decreciente, razonablemente se afirma como una consecuencia, en parte, de la inmigración de los colonos al área, y en parte como consecuencia de la concentración de los Machiguenga en unas pocas Comunidades Nativas; esto es, se le considera resultado del incremento de la presión sobre los recursos naturales existentes.

Se puede distinguir ocho diferentes métodos de pesca, definidos de acuerdo al instrumento empleado. Estos son: pesca con arco y flecha, con arpón, con anzuelo y cordel, con veneno, con dinamita, con trampas, con las manos, con machete y con mangas de red. No se usan todos los métodos en cada localidad y algunos como la pesca con arco y flecha y con arpón, por lo general son muy raros. Hasta cierto punto el método escogido depende del tiempo del año y de la condición del agua en la cual se va a pescar. Otro criterio que determina el método a emplear es el sexo, pues algunos instrumentos sólo pueden ser usados o por hombres o por mujeres.

Aunque la pesca generalmente se realiza en grupos de variados tamaños, la apropiación del pescado es individual. Esto también se refiere a la pesca con veneno que, en cualquier parte de la amazonía, con frecuencia es asociada con un modo comunal de explotación.

Joaquín Barriales (1977: 34, 48), describe la pesca con veneno realizada entre los del bajo Urubamba, como una empresa colectiva donde lo pescado es reunido y luego redistribuído a todos los miembros de la comunidad. Sin embargo, entre los Machiguenga del Alto Urubamba la condición es diferente, lo que puede ser ilustrado por el siguiente ejemplo.

La pesca con veneno se hace casi exclusivamente durante la estación seca, cuando los ríos están bajos y fáciles de represar. El veneno usado es el rotenone contenido en la liana barbasco (kogi, Clebadium vargasii), que al parecer crece principalmente en las chacras antiguas. Hoy en día los Machiguenga no siembran la liana Kogi, pero sostienen que sus antepasados sí lo hacían y es por esto que encuentran la liana en los lugares donde, en otro tiempo, estuvieron las chacras.

Los sitios donde crece la liana no están controlados por nadie; y cualquiera, sin restricciones, es libre de servirsé a sí mismo. Esto ha llevado a una notable disminución en la disponibilidad de la liana kogi en un área como Koribeni que tiene una concentración de Machiguenga y migrantes, todo los cuales usan la liana para pescar.

Toda pesca con kogi comienza con la selección de un sitio apropiado para pescar. Este puede estar en cualquier parte, pero se evita los lugares recientemente pescados ya que allí la pesca será muy reducida. La liana es recolectada por el hombre que organiza la pesca, y transportada al sitio donde ésta tendrá lugar. El organizador prepara el veneno durante la noche y al amanecer se harán presentes los que deseen 
tomar parte en la pesca, antes de que el veneno sea vertido en el río. La gente espera esparcida en las orillas a lo largo del río y en grupos familiares. Cuando el veneno ha sido vertido en el agua y los primeros peces aparecen flotando asfixiados en la superficie, la gente entra en el agua para coger con las manos tanto pescado como sea posible. Como se decía más arriba, lo pescado no se reúne y se distribuye entre los partícipantes, sino que lo cogido por una persona cualquiera pertenece sólo a esa persona y él o ella es libre de conservarlo o de darlo.

Esto significa que aquel que organiza la pesca puede no obtener nada o muy poco del producto total. En una ocasión particular un solo hombre organizó una pesca en la que, por su cuenta, construyó las trampas y preparó el veneno; una considerable cantidad de trabajo. Sin embargo, trabajó sólo para conseguir un pez grande y unos pocos pequeños. Luego, y por un largo tiempo, se quejó de la mezquindad de la gente que no había compartido con él lo que había conseguido; después de todo, él había hecho todo el trabajo pesado. Se quejaba especialmente cuando podían oírlo los que habían cogido más peces en esa ocasión y se prometía a sí mismo no organizar nunca más una pesca, sino sólo participar en el botín.

La actual escasez de peces en los ríos puede estar provocada por el incrementó del empleo de dinamita para la pesca. El efecto del uso de la dinamita y del veneno es casi el mismo: los peces son aturdidos o asfixiados y cogidos cuando flotan en la superficie. Los dos métodos son razonablemente comparables en relación al trabajo invertido. Sin embargo, hay una importante diferencia: pescar con dinamita puede ser planeado con el conocimiento de un limitado número de personas, mientras que los planes para echar veneno a un río implican un despliegue de personas enteradas. Además, ésto significa que sólo la familia del dinamitador estará en condiciones de sacar ventaja del pescado obtenido; ésto puede llevar a creer que dicha familia estaría abundantemente provista de pescado. Sin embargo, este no es el caso debido a la escasez de peces en los ríos.

Como ilustración de la severidad de la situación, la última vez que fui testigo de una pesca con dinamita en el río Koribeni (lugar que generalmente es considerado rico en pesca), la captura entera consistió en un solo "boquichico" (Shimaa, Prochilodus, magdalenae) que pesaba aproximadamente de 2.5 a 3 kilos. Esto tuvo lugar en Octubre, esto es, cuando la mayoría de las pescas con veneno ya han sido hechas y la existencia de peces en los ríos ha disminuído. Pero de todos modos fue una captura excepcionalmente mala; anteriormente había visto lograr por lo menos de cinco a diez ejemplares del mismo tamaño, cogidos junto con muchos peces más pequeños.

\section{La Recolección}

La recolección es la menos notable de las actividades de subsistencia de los $\mathrm{Ma}$ chiguenga. Además, no es vista como una actividad particular, pues nadie se asigna 
el propósito principal de recoger hierbas o plantas. Así, la gente recolecta lo que encuentra "recolectable" cuando están realizando otras actividades, o salen para recolectar una especie en particular como, por ejemplo, la enredadera Aydhuasca (Kamarampi, Banisteriopsis caapi) para hacer alucinógenos, o las vainas de Genipa (potsotaroke, Genipa americana) para fabricar tinte negro para colorear algodón. La gente conoce muy bien dónde se pueden encontrar estas plantas y como no hay una demanda muy grande; no hay necesidad de cultivarlas en las chacras.

La "recolección" de alguna larvas, ejemplos notables el tseiro y el tsuri (no identificadas), constituye un caso especial en tanto es una actividad intermediaria entre la recolección y la crianza. Algunos árboles y palmeras son cortados a propósito para que las mariposas puedan poner sus huevos en los troncos podridos. Al final de la estación seca y al comienzo de la lluviosa estos troncos son escudriñados en busca de larvas. Generalmente estos árboles y palmeras se encuentran en las chacras rozadas que aún no han sido quemadas. Así, la "crianza" de larvas coincide con el ciclo de cultivo y quizá, igualmente podría ser descrito bajo el rubro horticultura.

De cualquier modo, una amplia variedad de frutos, nueces, granos e insectos son recolectados, pero todos de manea casual. Aún cuando la gente no está desinteresada en los artículos recolectados, con frecuencia se les considera como meros "bocadillos" y frecuentemente son consumidos inmediatamente en el sitio. De este modo, la recolección tiene lugar cuando la oportunidad se presenta, y lo "recolectable" pertenece a quien lo encuentra.

En resumen, el uso de los Machiguenga de su ambiente natural es extensivo, en el sentido que emplean una amplia variedad de recursos para su subsistencia y en el que ningún recurso simple es explotado intensamente. Al lado de la división sexual del trabajo, no hay especialización respecto a las actividades de subsistencia, y casi todos son capaces de cubrir sus propias necesidades y las de sus familias dentro de los límites puestos por la división sexual del trabajo.

Aunque la yuca es el componente principal de la mayoría de las comidas, la dieta es variada y el status nutricional es bueno ( $\mathrm{cf} A$. Johnson and C.A. Behrens 1982). Sin haber hecho ninguna investigación comparativa, parece evidente que el status nutricional, en general, es mejor entre los Machiguenga que entre los colonos sembradores de café en las cercanías. Entre estos últimos es muy común ver signos de malnutrición, deficiencias de proteínas y vitaminas, particularmente entre los niños y las mujeres. Aún cuando los colonos se den cuenta que los Machiguenga están en mejor posición, ellos se sienten superiores; en parte porque ellos "trabajan", esto es, ellos ganan dinero, ellos no sólo se "divierten" como dicen que hacen los Machiguenga, quienes pueden ir a cazar o pescar cuando les provoca hacerlo. 


\section{NOCIONES DE RECURSOS Y TRABAJO}

En la introducción de este artículo, la incorporación de trabajo a los objetos enfatizaba respecto a la definición de relaciones de propiedad. De acuerdo con eso, en lo que sigue mostraré cuán crucial es el gasto de trabajo para los Machiguenga, como definen ellos las relaciones de propiedad, y como están interrelacionados el gasto de trabajo y la propiedad.

La tierra ha estado teniendo una posición central entre los diferentes recursos tratados arriba. La "tierra" se traduciría en Machiguenga como Kipatsi, que justamente es un concepto que también connota diferentes metamorfosis de la tierra. La tierra en la que vivimos es Kipatsi (2), pero también es el terreno en que estamos, así como el suelo que constituye el terreno. De esta manera, todo lo que tenemos bajo nuestras plantas es Kipatsi. Los diferentes significados dados aquí a la palabra Kipatsi, no son ni metonimias ni metáforas para los Machiguenga; son sólo diferentes apariencias de un mismo fenómeno. Como fenómeno, Kipatsi es omnipresente y eterno y como el agua y el aire; la tierra es para todos y nadie puede poseerla.

Kipatsi traducida como "terreno" y "suelo" puede ser más especificada y descompuesta en subcategorías. Así se distinguen diferentes clases de terreno (tales como: "colina", "bosque", y "chacra"), diversos suelos (por ejemplo: "rojo", "negro", y suelos "arenosos"). Sin embargo no son nada sino subcategorías y todas continúan siendo Kipatsi, así como el suelo constituye el mundo en que vivimos.

En contraste con el concepto "genérico", las subcategorías de Kipatsi no son omnipresentes, por tanto tienen las mismas características temporales. Las colinas, los bosques y los diferentes suelos "siempre" han estado allí y continuarán estando allí no importa lo que el hombre quiera y pueda hacer (3).

Son categorías naturales y como tales están fuera de la esfera del hombre y la sociedad. Además, no se ha invertido ningún trabajo en ellos y, como consecuencia, lo que crece y vive allí en su estado natural no puede ser poseído o monopolizado por nadie.

Aunque la chacra también es una de las apariencias que Kipatsi puede tomar, aquella difiere en algunos aspectos importantes de las otras subcategorías. Por ejemplo, la chacra es solo un fenómeno temporal y no durará por mucho tiempo - a pesar que siempre habrá nuevas chacras que reemplacen a las antiguas. Además, la chacra no es algo dado por la naturaleza, antes bien, es creada por el hombre mediante el trabajo. En este contexto, se puede señalar que las palabras para "chacra" tsamarintsi, y el verbo usualmente traducido como "trabajar", netsamatskira, están estrechamente relacionadas.

Sin embargo, como las otras subcategorías, la chacra continúa siendo Kipatsi y, por tanto, el terreno no puede ser poseído por nadie. Esto es, no puede ser vendido ni rentado, o ser alienado para o por alguien de alguna u otra manera. Por otro lado, 
ciertamente las chacras individuales pertenecen a alguien, pero hay que pensar que lo poseído no es el terreno, sino los cultivos allí plantados. En otras palabras, lo que es poseído es el fruto del trabajo, que puede ser apropiado por el consumo y el único derecho que corresponde sobre el terreno, es el derecho de explotarlo.

El derecho de explotar los diferentes recursos en Kipatsi es el ünico y el mismo derecho indiferente de los distintos objetos concernidos. Por lo tanto, en relación con los derechos no hay diferencia en cuanto a la caza, la pesca, la recolección o la horticultura. Todos los diferentes objetos son apropiados con el trabajo invertido y quien invierte su trabajo también tiene derecho a gozar de los frutos del mismo.

Aquí llegamos al caso del trabajo, que es conceptualizado por los Machiguenga en una manera particular. Mientras que nosotros tendemos a ver el trabajo en la perspectiva del producto final, ellos lo consideran desde la perspectiva de los diferentes componentes, de los momentos del trabajo.

Así, por ejemplo, mientras nosotros veríamos la chacra como un proceso constituído de varios momentos, incluyendo roza, quema y siembra; los Machiguenga consideran estos diferentes momentos como procesos concluídos y terminados. Desde nuestra perspectiva, lo que ellos producen son rozas, chacras y siembras, ya que los objetos producidos pertenecen al productor; esta división del proceso de producción en sus momentos de trabajo separados, es de una importancia central para los Machiguenga al decidir quién posee qué. Si, por ejemplo uno tiene que preguntar a un Machiguenga quién es el dueño de las plantas de yuca que crecen en su chacra, podría contestar que él es el dueño, pero si se le pregunta quién es el dueño de yuca cosechada, él contestaría que pertenecen a su esposa. El pone su trabajo en la siembra de las plantas de yuca y por tanto ellas le pertenecen.

Como consecuencia él decide qué hacer con la yuca y, generalmente, decide que las mujeres de su familia deben cosecharla. Sin embargo, él puede enajenar todo o parte de la cosecha y aunque su esposa puede regañarlo, lo único que a ella le queda por hacer es tratar de hacerlo cambiar de decisión. Por lo tanto, el hombre tiene pleno control sobre sus plantas, pero tan pronto como se cosecha la yuca se transforma de planta a tubérculo, es decir, ha sido invertido ún nuevo trabajo y un nuevo objeto con un nuevo dueño hà sido producido.

El nuevo producto, a saber, los tubérculos de yuca, ahora pertenecen a la mujer y ella asume, como antes lo hizo el hombre, pleno control sobre el producto por el derecho que le da el trabajo que ha invertido en el proceso de producción, en la cosecha.

Se mantiene la misma regla para todos los otros procesos de producción. El animal cazado por un hombre le pertenece hasta que lo entrega a alguna mujer para su preparación (4). Después, la comida le pertenece a ella hasta que la distribuye, entonces inmediatamente pierde su control sobre la comida entregada. El hombre produce carne cruda y la mujer la transforma en comida. De manera similar, el pescado 
significa la producción de pescado crudo que pertenece a quien lo ha cogido; con su preparación se transforma en comida y entonces pertenece a quien lo ha preparado. Aunque pescar con veneno denota una considerable cantidad de trabajo de parte de los que preparan las trampas y el veneno, esta labor no confiere ningún derecho especial en la pesca. Esto fue demostrado en el caso relatado más arriba, donde todos los preparativos fueron hechos por un solo hombre sin que ésto le asegurara una parte razonable del pescado cogido en esa ocasión. La producción de trampas y la captura de peces son consideradas como dos procesos distintos y los derechos de propiedad conferidos por la cantidad de trabajo sólo atañen al producto inmediato del trabajo, es decir, a las trampas o al pescado.

En un trabajo sobre sociedad de cáza y recolección, James Woodburn (1982), postula la siguiente hipótesis: lo que distingue a los cazadores y recolectores de los agricultores, es que entre los primeros el proceso de trabajo es una actividad de retorno inmediato, mientras que entre los últimos es una actividad de retorno diferida. En otras palabras, el rendimiento del trabajo de cazadores y recolectores es apropiado inmediatamente por el consumo, en contraste con los agricultores que tienen que esperar el tiempo de la siembra hasta la cosecha antes de poder consumir el fruto de su trabajo. Desde esta perspectiva "temporal" en el trabajo, que coincide con la forma como tendemos a considerar el proceso de trabajo, la agricultura de chacra de los Machiguenga los situaría en la categoría de economías de retorno diferido. Sin embargo, aplicando su propio modo de concebir el proceso de trabajo, encontramos que caerían en la categoría de economías de retorno inmediato.

En términos generales, la distinción de Woodburn corresponde a la distinción que hace Claude Meillassoux entre la tierra como "sujeto" o como "instrumento" de trabajo. Meillassoux propone que "la diferencia radical observada entre una economía de caza y recolección y una economía agrícola, está relacionada al hecho de que la primera usa la tierra como un "sujeto de trabajo" mientras que la segunda usa la tierra como un "instrumento de trabajo". Como la distinción de Woodburn, la distinción de Meillassoux sitúa a los Machiguenga entre los agricultores, lo que es igualmente válido para dicho grupo desde fuera de nuestra percepción etnocéntrica del proceso de trabajo.

Sin embargo, si vemos las propias concepciones de trabajo de los Machiguenga, estas distinciones ya no son válidas para ellos. Ambos, Meillassoux y Woodburn asumen que las sociedades agrícolas son economías de retorno diferido, donde la tierra es un instrumento de trabajo, de esta suerte la categoría en la que los Machiguenga caerían, inevitablemente debe desarrollar una estructura social jerárquica en contraste con el igualitarismo de las sociedades de cazadores y recolectores.

A pesar de la atropellante importancia de la agricultura de subsistencia, la cultura Machiguenga está atravesada por un ideal igualitario, rasgo que comparte con la mayoría de las otras sociedades de la selva (cf. Steward 1948: 528), y las únicas distinciones formales hechas son aquellas que se basan en la edad, sexo y relaciones de status. 
Esto demostraría que observar sólo el desarrollo de las fuerzas productivas es insuficiente y lleva a un análisis muy mecánico. También debemos considerar otros aspectos de la estructura social que pueden determinar la evolución social.

Considerando la importancia de la interrelación entre cantidad de trabajo y relaciones de propiedad, se puede trazar un interesante paralelo entre los Machiguenga y los Merina de Malagasy. Maurice Bloch (1975) demuestra cómo el parentesco y la trascendencia juegan un rol importante entre los Merina, para definir allí las actuales condiciones de tenencia de la tierra. Los Merina, quienes durante el siglo XIX se expandieron en bosques primitivos, representan y legitimizan los actuales derechos de tenencia de la tierra como una devolución ancestral de la tierra a los descendientes de aquellos que una vez rozaron el monte.

Aunque las relaciones de uso de los recursos sociales de los Merina y Machiguenga son bastante distintas unas de otras, entre los Merina se posee privadamente, pero entre los Machiguenga no se puede poseer; el argumento de la devolución ancestral, es usado en ambas sociedades para explicar las respectivas condiciones de tenencia de la tierra.

Refiriéndose a los Machiguenga, Joaquín Barriales (1977: 27) señala que:

"El concepto de poblado, para el Machiguenga, no es otro que su definitiva unión con los ancestros. Poblado es todo lugar donde vive él, donde vive su paisano y alli donde puede acudir cuando lo desee. Poblado es todo su habitat con el que se identifica... es la casa, la chacra, el río, el monte, porque en todos estos lugares viven los Machiguenga, los de hoy y los de ayer, por eso incluye el concepto de poblado el cielo y el subsuelo, pues allí moran cientos de paisanos".

Entonces, ¿Cómo son percibidos los ancestros entre los Machiguenga? Si observamos el sistema de terminología de parentesco, encontramos que los abuelos son Џlamados sbaónka (FF, MF) y sbainka (FM, MM). Además, estos términos son dados a cada persona de tres generaciones y más por encima de ego. Esto va acompañado de una "amnesia genealógica" muy extendida y la memoria de los actuales ancestros raramente se extiende más allá de la segunda generación a partir de ego. Con el recuerdo borroso de los lazos de parentesco, los ancestros individuales se funden y están sumergidos en un corpus de ancestro anónimo que todo lo contiene o incluye.

Consecuentemente, toda persona de tres generaciones sobre ego es un miembro potencial de su parentela y por tanto, son tratados como ancestros reales. Como todos tienen el mismo sbaónka y shainka como ancestros, no es posible reclamar los mismos derechos precedentes a la herencia como pueden ser reclamados por los niños en relación a la propiedad de sus padres. Por el contrario, todos tienen el mismo derecho a la herencia o, más bien, ninguno puede reclamar un derecho más grande que algún otro a aquellos recursos fundados en Kipatsi. Mientras que para los padres es posible legar el producto de su trabajo en favor de sus hijos, ha pasado demasiado tiempo con las actuales técnicas agrícolas como para argüir por la devolución de tie- 
rras desde la generación de los abuelos. En otras palabras, todos los recursos son accesibles para todos y la única cosa que puede ser reclamada son los derechos de explotación y un derecho al fruto del trabajo propio.

\section{MACHIGUENGA/COLONO. RELACIONES SOCIALES EN EL USO DE LOS RECURSOS}

Al comienzo de este trabajo, mencioné brevemente los problemas que las sociedades nativas de la selva están enfrentando hoy, con la coexistencia de dos sistemas contradictorios de uso de los recursos: el indígena y el occidental. Quiero retornar el asunto y a las consecuencias de esta situación para los Machiguenga del Alto Urubamba.

Para comenzar, pueden distinguirse dos clases de problemas: aquellos que son el resultado de relaciones incompatibles dentro de la sociedad Machiguenga, y los que son el resultado de relaciones externas incompatibles.

La primera clase de problemas está relacionada a los cambios en los patrones de producción agrícola. Generalmente los cultivos de subsistencia son anuales y además son compatibles con el sistema de barbecho de la tradicional agricultura de chacra. La introducción de los cultivos comerciales perennes ha significado que disminuya la velocidad de rotación de la tierra, en vez de retornar al barbecho después de 3 a 5 años como en las chacras con cultivos de subsistencia; los campos plantados con cultivos comerciales siguen produciendo después de diez años.

Hasta ahora los efectos de este desarrollo en las relaciones sociales del uso de los recursos han sido menores, ya que aún existe una provisión de tierra que puede ser empleada.

Sin embargo, ya hay personas que han manipulado para adquirir grandes áreas de las mejores tierras agrícolas, con la consiguiente desventaja para otros. Fácilmente se ve cómo este patrón de distribución de la tierra devendrá aún más pronunciado en el futuro y también, como consecuencia directa, cómo ésto llevará a la emergencia de clases sociales y a una profundización de la desigualdad económica.

La segunda clase de problemas apremiantes están en la actual situación política, donde la migración a la montaña es impulsada y activamente promovida por el gobierno. Lado a lado, existen dos sistemas de tenencia de tierra enteramente diferentes, uno permitiendo la apropiación privada de la tierra, el otro negando la posibilidad de que alguien sea capaz de poseer algo como la tierra. De acuerdo al primer sistema la tierra es una mercancía, para el segundo ésta es un recurso. 
Actualmente, la situación de dos sistemas de tenencia de tierras coexistiendo está llevando a conflictos no sólo entre los nativos y los migrantes, sino también entre las mismas comunidades nativas. Relataré aquí un ejemplo de una de las comunidades nativas del Alto Urubamba, que pone en evidencia la situación tal como existe. En este caso, un individuo sin nada más que la mejor de las intenciones, involuntariamente, creó grandes problemas para sus compañeros Machiguenga (5).

Un mejorero (6), con agudos problemas familiares, quería separarse de su esposa y comenzar de nuevo. A fin de conseguir dinero para su nuevo comienzo vendió en 1981 su mejora a un rico comerciante. La venta fue ilegal porque: 1) la Comunidad nativa dueña de la tierra no había sido notificada, 2) la tierra no había sido valorizada por la agencia de reforma agraria, prerequisito para todas las transacciones de tierra de acuerdo a la ley, y 3) la mejora había sido adquirida por esposo y esposa juntos, y la esposa no había dado su consentimiento para la transacción, ni recibido ninguna compensación por la tierra.

Inmediatamente después de cerrar el trato, la comerciante ya había hecho nuevas plantaciones, ya había llevado ganado y construído viviendas para ella y sus trabajadores. Cuando la Comunidad nativa se enteró de la transacción, prontamente notifícó al comprador que la venta era declarada nula y tenía que desalojar, que las casas recientemente construídas debían ser demolidas en el acto, el ganado debía ser trasladado y desarraigadas las nuevas plantaciones.

El comprador desatendió la notificación y continuó trabajando la tierra como si nada hubiera pasado. En una asamblea extraordinaria, reunión convocada con un único punto de agenda: la venta, la comunidad decidió poner un alto a la pretensión de los compradores ilegales. El mismo día todos juntos fueron a la tierra en disputa, donde destruyeron las nuevas plantaciones y demolieron las nuevas viviendas. Sin embargo, el comprador continuó; se construyeron nuevas casas, se hicieron nuevas plantaciones y se plantaron árboles de frutos cítricos.

En una nueva asamblea de la comunidad se decidió que se debería tomar nuevas acciones, a fin de hacerlas más efectivas y se propuso que el juez de paz y la policía fueran invitados a asistir. Sin embargo, el juez de paz declaró que él no podría estar presente sin el permiso de las altas autoridades judiciales (es decir, del juez de Primera Instancia), y como él no podría obtener el permiso para el día en que la acción estaba planeada, se decidió no llamar tampoco a la policía.

En la mañana del día fijado, los miembros de la comunidad se reunieron y fueron al terreno en disputa para repetir su acción. Esta vez encontraron a dos policías amenazando al próximo Machiguenga que se acercara con el arresto inmediato y la llegada de más policias si ellos no se retiraban en el acto.

El usurpador de la tierra había llamado a la policía (y les reclamaba abrir fuego), después de haber sido prevenida por un miembro de la comunidad. A pesar de la presencia de la policía la acción fue llevada a cabo. Por la tarde la policía volvió a 
la comunidad y esta vez fueron arrestados varios hombres y llevados al puesto de policía para el interrogatorio.

Más adelante recogí estos datos, sin saber, del "acusado" que había "traicionado" a su Comunidad nativa y a sus compañeros comuneros. Como en esa época yo no sabía de la "traición" pues recién había llegado, se me dijo que un pedazo de tierra no tenía importancia, que no había que preocuparse y que la mujer podía tener la tierra si la quería. Ya que la comunidad territorialmente es bastante pequeña, repliqué que toda la tierra debería ser cultivada rápidamente.

Mi informante no se preocupó por ésto porque, según él, había mucha tierra abandonada. Respondí que casi toda la tierra buena de la comunidad ya estaba cultivada. Con ésto tuvo que estar de acuerdo pero continuó sosteniendo que en lo profundo del monte siempre había buena, más que suficiente para cualquiera, entonces por qué preocuparse por esta pequeña parcela.

El conflicto era innecesario para este hombre, no sólo porque había mucha buena tierra que no se usa, sino también porque la tierra como tal no puede ser poseída. El veía el asunto desde la perspectiva Machiguenga de las relaciones sociales del uso de los recursos.

Para él, la comerciante había estado bien y no podía entender por qué los Machiguenga no podían ser buenos con ella y dejarle usar la tierra que de todos modos, el antiguo cultivador había abandonado y entregado a ella.

La respuesta de este hombre es interesante porque demuestra la vulnerabilidad de las comunidades nativas Machiguenga y cómo astutamente los migrantes pueden usurpar sus tierras. Sin embargo, ésto también demuestra el hecho alarmante de que a fin de sobrevivir como un grupo étnicamente distinto en las condiciones presentes, los Machiguenga tienen que asimilarse a la sociedad nacional y desistir de su propio modo de vida. De aquí que, a pesar de cualquier cosa que los Machiguenga hagan, al final quedarán como los perdedores. (Traducido por: Guillermo Nelson).

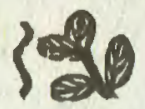

(1) En Machiguenga no existe el infinitivo, por tanto, los verbos se dan en la primera persona singular y en tiempo presente.

(2) De acuerdo a la Cosmología Machiguenga, el cosmos está constituido por un mundo de cinco "capas", dentro de las cuales nosotros vivimos en la tercera, es decir, en la que está en el medio.

(3) Los Machiguenga, como muchos otros pueblos, tienen concepciones de un fin del mundo cataclísmico. Sin embargo, estas concepciones no incluyen (hasta ahora) tecnología moderna, signos de una destrucción apocalíptica.

(4) Bajo condiciones normales, en la mayorla de los casos las mujeres preparan la comida. Cuando no hay mujeres disponibles para cocinar el hombre puede preparar su propio alimento.

Sin embargo, no cocinarán, sino que freirán. Por supuesto, bajo circunstancias, es el hombre quien prepara la comi$\mathrm{da}$, quien la posee, entonces, aún es el único que pone el trabajo en un objeto que posee.

(5) Estoy muy agradecida y en deuda con el padre Nemesio de Koribeni por esta información.

(6) Un mejorero, es una especie de arrendatario que sólo puede trabajat en plantaciones ya existentes. Está prohibido ha. cer nuevas plantaciones o cambiar el terreno tomado de alguna manera. La tierra sólo puede ser sembrada por el dueño que en este caso es la comunidad nativa. De acuerdo a la ley, el contrato de una mejora, tierra arrendada a un mejorero, puede ser vendida sólo a otro mejorero, y bajo las mismas condiciones de tenencia; ésto solamente si el dueño, que tiene la primera opción en la compra, consiente la operación. 
z

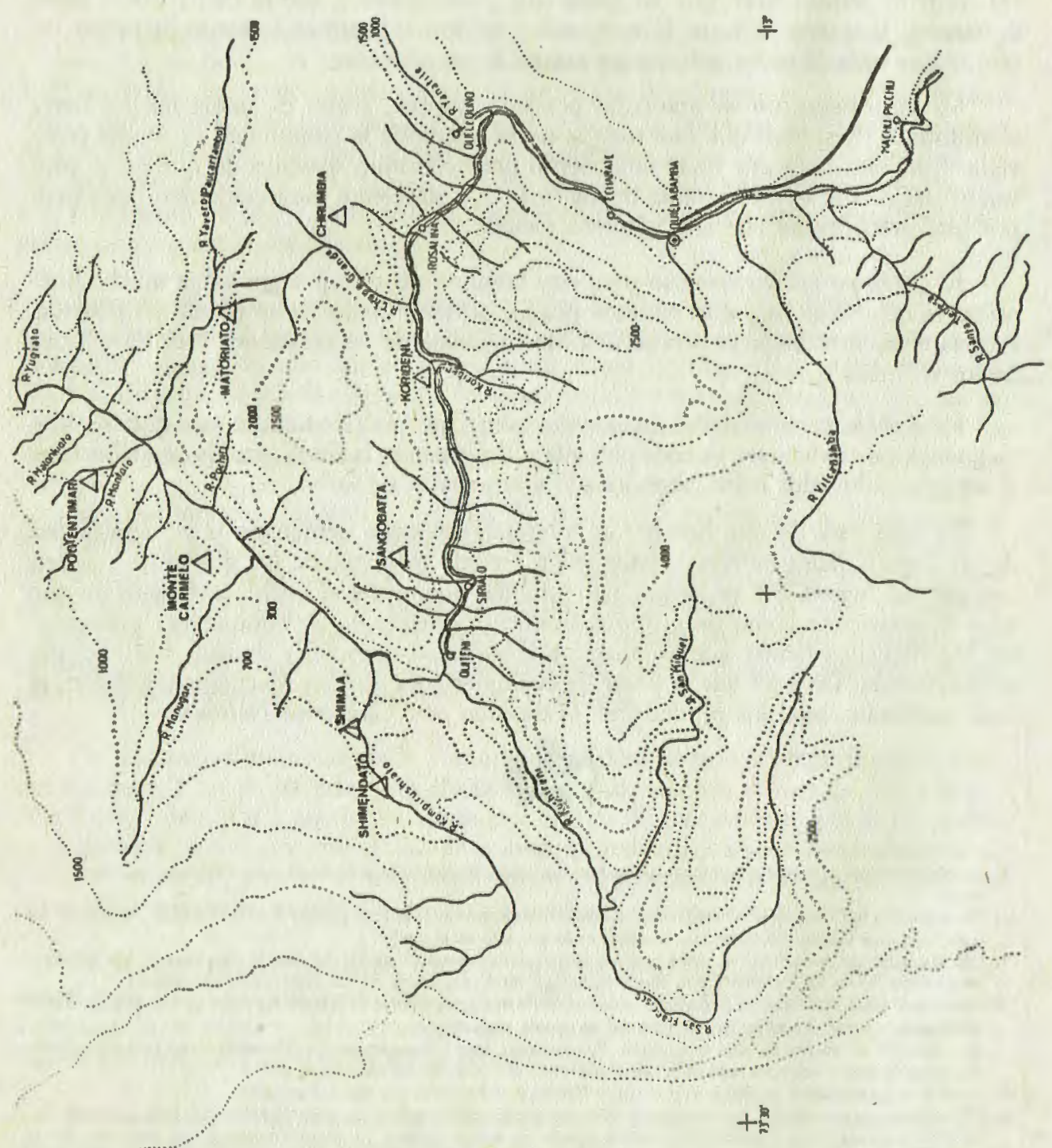

Mapa de la Zona del Alto Urubamba, Provincia de la Convención, Dpto. de Cusco. 


\section{B I B L I O G R A F I A}

BARRIALES, JOAQUIN

1977 Matsigenka.

Lima.

BLOCH, MARC

1965 Feudal Society, Vol. 1 London.

BOHANNAN, PAUL

1963 "'Land', "Tenure', and Land Tenure," in African Agratian Systems, ed. by. D. Biebuyck, pp. 101-111, Oxford.

BRADBY, BARBARA

1977 "The Non-Valorisation of Women's Labour", Critique of Anthropology, 3 (-10): 131-138.

ELLEN, ROY

1977 "Resource and Commodity: Problems in the Analysis of the Social Relations of Nuaulu Land Use," Journal of Anthropological Research, 32 (1): 50-72.

FIRTH, RAYMOND

1979 "Work and Value: Reflections on ideas of Karl Marx", in Social Anthropology of Work, ed. by S. Wallman, ASA Monograph 19, pp. 177-206, London.

FORD, T.R.

1955 Man and Land in Perú Gainsville.

GLUKMAN, MARX

1965 The Ideas in Barotse Jurisprudence Manchester.

GODELIER, MAURICE

1969 "La monnaie de sel des Baruya de Nouvelle-Guinée," L'Homme, IX (2): 5-37.

1978 "Territoru and Property in Primitive Society", Social Science Information, 17 (3): 339-428.

JOHNSON, ALLEN

1982 "Reductionism in Cultural Ecology: The Amazon Case," Current Anthropology, 23 (4): 413-428.
1983 "Machiguenga Gardens," in Adaptive Responses of Native Amazonians, ed. by R.B. Hames and W.T. Vickers, pp. 29-63, New York.

JOHNSON, ALLEN and CLIFFORD A. BEHERENS

1982 "Nutritional Xriteria in Machiguenga Food Production Decisions: A Linear. Programming Analysis," Human Ecolo. gy, 10 (2): 167.189 .

JOHNSON, ORNA ROTH

1978 Interpersonal Relations and Domestic Authority Among the Machiguenga of the Peruvian Amazon. Unpubl. Ph. D.

- Thesis, Colombia Universiry (Mimeo.)

MARX, KARL

1954 The Capital, Vol, 1 Moscow.

MEILLASSOUX, CLAUDE

1978 "The Social Organization of the Peasantry: The Economic Basis of Kinship," in Relations of Production, ed. by D. Seddon, pp. 159-169, London.

ROSENGREN, DAN

1983 "Proximity and Interaction: The Case of the Matsigenka of the Upper Urubamba, Southeastern Peru," Göteborgs Ennografiska Museum Arstryck 1981/ 82, pp. 48-63, Gothenburg.

STEWARD, JULIAN $\mathrm{H}$.

1948 "Tribes of the Montaña: An Introduction," in Handbook of South American Indians, Vol. 3: 507.533, ed. by J.H. Steward, Washington, $D_{1} C$.

WOODBURN, JAMES

1982 "Egalitarian Societies," Man (N.S.), 17 (3): $431-451$. 